\title{
Extent, regional variation and impact of gynecologist payment models in routine pelvic examinations: a nationwide cross- sectional study
}

Ingvild Mathiesen Rosenlund ${ }^{1 *}$, Linda Leivseth², Ingard Nilsen ${ }^{3}$, Olav Helge Førde ${ }^{2,4}$ and Arthur Revhaug ${ }^{1,5}$

\begin{abstract}
Background: Based on moderate quality evidence, routine pelvic examination is strongly recommended against in asymptomatic women. The aims of this study was to quantify the extent of routine pelvic examinations within specialized health care in Norway, to assess if the use of these services differs across hospital referral regions and to assess if the use of colposcopy and ultrasound differs with gynecologists' payment models.

Methods: Nationwide cross-sectional study including all women aged 18 years and older in Norway in the years 2014-16 $(2,038,747)$. Data was extracted from the Norwegian Patient Registry and Statistics Norway. The main outcome measures were 1. The number of appointments per 1000 women with a primary diagnosis of "Encounter for gynecological examination without complaint, suspected or reported diagnosis." 2. The age-standardized number of these appointments per 1000 women in the 21 different hospital referral regions of Norway. 3. The use of colposcopy and ultrasound in routine pelvic examinations, provided by gynecologists with fixed salaries and gynecologists paid by a fee-for-service model.
\end{abstract}

Results: Annually 22.2 out of every 1000 women in Norway had a routine pelvic examination, with variation across regions from 6.6 to 43.9 per 1000. Gynecologists with fixed salaries performed colposcopy in 1.6\% and ultrasound in $74.5 \%$ of appointments. Corresponding numbers for fee-for-service gynecologists were $49.2 \%$ and $96.2 \%$, respectively.

Conclusions: Routine pelvic examinations are widely performed in Norway. The variation across regions is extensive. Our results strongly indicate that fee-for-service payments for gynecologists skyrocket the use of colposcopy and increase the use of ultrasound in pelvic examinations of asymptomatic women.

Keywords: Routine pelvic examination, Unwarranted examination, Fee-for-service, Regional variation, Ultrasonography, Colposcopy

\section{Background}

Based on moderate quality evidence, routine pelvic examination is strongly recommended against in asymptomatic women [1-3], as is screening colposcopy [4] and routine screening for ovarian cancer in asymptomatic women [5-7]. In the Prostate, Lung, Colorectal and Ovarian Cancer Screening Randomized Controlled Trial, including 78,000 women, bimanual examination of the

\footnotetext{
* Correspondence: ingvild.m.rosenlund@uit.no

${ }^{1}$ Department of Clinical Medicine, UiT The Arctic University of Norway,

Tromsø, Norway

Full list of author information is available at the end of the article
}

ovaries was discontinued as no ovarian cancer was detected merely by palpation [8]. Use of screening CA 125 and transvaginal ultrasound does not reduce ovarian cancer mortality $[8,9]$ and is advised against $[5,10]$. High rates of colposcopy do not decrease cervical cancer incidence or mortality [11]. False positive screening test results are associated with harm. Women screened for ovarian cancer have a $33 \%$ increased risk of oophorectomy [8] and for every screening detected cancer ten women undergo surgery following a false positive ultrasound examination [9]. Ultrasound of the pelvis should not be performed unless clear indications are present 
[12]. Pelvic examination prior to provision of hormonal contraceptives does not identify women who should avoid these contraceptives and is not recommended as routine practice [13].

The Norwegian public health system is well developed with access for all inhabitants. All citizens have a legal right to equal access to good quality health care [14]. All citizens are entitled to a regular general practitioner who, if necessary, refers the patient to specialized care. Apart from abortions, women themselves cannot make an appointment at a publicly reimbursed gynecologist without a referral.

The municipalities of Norway are allocated into 21 different hospital referral regions. Each region has a defined health enterprise responsible for providing specialized health care for their inhabitants. The health enterprises collaborate with private physicians to varying degrees. In Norway all gynecologists at public hospitals are paid a fixed salary, while a fee-for-service model pays private gynecologists that collaborate with the health enterprises.

\section{Methods}

Aims

1. To quantify the extent of routine pelvic examinations within specialized health care in Norway.

2. To assess if the use of these services differs across hospital referral regions.

3. To assess if the use of colposcopy and ultrasound differs with gynecologists' payment models.

\section{Study design}

Nationwide cross-sectional study on routine pelvic examinations within specialized health care in Norway.

\section{Setting}

The Norwegian Patient Registry (NPR) contains health reports on every appointment within publicly funded specialized health care in Norway. Both public hospitals and private gynecologists that collaborate with the health enterprises report diagnoses of every patient appointment to NPR. The appointments are linked to the patients through the personal identification number of all inhabitants of Norway. Data from NPR is used for central planning of specialized health care, activity based financing, quality indicators, and health care research. Through Centre for Clinical Documentation and Evaluation (SKDE) we had access to reports for 2014-16 in addition to annual population statistics from Statistic Norway. One author (LL) had access to indirect personally identifiable data from NPR. All analyses and results are anonymous.

\section{Participants}

We included all Norwegian women aged 18 years and older in Norway in the years 2014-16 ( $n=2,038,747)$.

\section{Variables and data sources}

In this study private gynecologists who get public reimbursement are for simplicity called "fee-for-service gynecologists." The term "fixed salary gynecologists" is used for gynecologists working in public hospitals, as the salaries of these gynecologists are independent of quantity of care. Data from privately out-of-pocket paid gynecologists' practice is not included in the study as such data is not recorded in Norway.

Both fixed salary and fee-for-service gynecologists used the International Classification of Diseases version 10 (ICD-10) for reports to NPR. The Norwegian versions for 2014-16 were in use during the study years. The three versions are identical for the codes we have studied [15]. All gynecologists also reported the municipality and city district code for the patients' residency. We used these codes to allocate appointments to the different hospital referral regions.

We defined routine pelvic examination as a primary diagnosis of ICD-10 Z01.4; "Encounter for gynecological examination without complaint, suspected or reported diagnosis." Cervical screening was defined as a primary diagnosis of the ICD-10 code Z12.4; "Encounter for screening for malignant neoplasm of cervix."

For hospital appointments colposcopy was defined by the allocation of the code LXE00 (colposcopy) in the 2014-16 versions of The NOMESCO Classification of Surgical Procedures (NCSP) [16]. Ultrasound was defined by the allocation of any of the codes LXDE05 (transvaginal ultrasound), SLXOBK or SLXOAK (transvaginal ultrasound of female pelvic organs) in the 2014-16 versions of the Norwegian Classification of Medical Procedures (NCMP) and the Norwegian Classification of Radiological Procedures (NCRP) [16]. For fee-for-service gynecologists colposcopy and ultrasound were defined either by the same procedure codes or by the allocation of the codes 208 (colposcopy) and 211c (transvaginal ultrasound) in "Tariff for publicly funded private physicians" versions 2014-16 [17]. In addition "complete examination" at a fee-for-service gynecologist was defined by the allocation of the tariff code 4b1 (allowance for complete examination performed by a specialist (after referral)).

Both publicly funded hospitals and fee-for-service gynecologists that get public funding are obligated to report surgical, medical, and radiological procedures according to NCSP, NCMP, and NCRP to NPR. In addition, fee-forservice gynecologists include tariff codes from "Tariff for publicly funded private physicians" in the reports sent to NPR. For each individual tariff code they report they get extra reimbursement. It is known that some fee-for-service 
physicians underreport NCSP and NCMP codes. Therefore we also included the more thoroughly reported tariff codes to the definition of colposcopy and ultrasound for fee-for-service gynecologists.

\section{Statistical analysis}

We obtained the age-standardized number of appointments for routine pelvic examination per 1000 women in Norway, and for the 21 different hospital referral regions. We also quantified the use of colposcopy and ultrasound in appointments for routine pelvic examination for women examined by gynecologists with fixed salaries and fee-for-service gynecologists, respectively. Differences between provider types were compared with Pearson's chi-square test. For fee-for-service gynecologists the number of appointments with codes for "Allowance for complete examination performed by a specialist (after referral)" was also examined. All numbers reported are the annual mean for 2014-16, unless otherwise stated.

There were missing data for municipality code in $0.5 \%$ (215) of appointments annually. As it is likely that patients do not travel far for routine pelvic examinations, we analyzed these appointments according to the referral region where the examination took place.

In additional analyses, we quantified the extent of cervical screening tests within specialized health care in Norway, and we examined if differences across hospital referral regions in routine pelvic examinations were depended on differences in cervical screening tests. We also examined if the use of colposcopy and ultrasound, and variation across regions in pelvic examinations were depended on registered secondary diagnosis.

We used SAS Enterprise Guide 7.1 [18] to analyze the data.

\section{Patient involvement}

Patients were not formally involved in the planning or conduction of the study. However, the subject under investigation involves all Norwegian adult women including the female authors of this paper.

\section{Results}

The estimated adult female population of Norway in the years 2014-16 was 2,038,747. Nationally there were 22.2 pelvic examinations per 1000 women (Table 1). Of women who received a pelvic examination during the years of investigation, the majority $(88.9 \%)$ had only one exam. The number of appointments per patient was 1.04 annually and 1.14 during the 3 year period.

Women aged 25-69 years constituted 87.6\% $(39,589)$ of appointments. Annually, 2.6\% $(38,065)$ of women aged 25-69 years had a routine pelvic examination, while
Table 1 Appointments for routine pelvic examinations in Norway, 2014-16

\begin{tabular}{lllll}
\hline Measures & 2014 & 2015 & 2016 & $\begin{array}{l}\text { Annual mean } \\
2014-16\end{array}$ \\
\hline Patients, n & 44,731 & 41,941 & 43,644 & 43,439 \\
Appointments, n & 46,619 & 43,534 & 45,382 & 45,178 \\
$\begin{array}{l}\text { Appointments per } \\
1000 \text { women }\end{array}$ & 23.1 & 21.3 & 22.0 & 22.2 \\
$\begin{array}{l}\text { Age, years, mean/ } \\
\text { median (range) }\end{array}$ & $47.7 / 47$ & $47.5 / 47$ & $47.1 / 46$ & $47.4 / 47$ \\
\hline
\end{tabular}

$0.97 \%$ (2231) of younger women and $0.96 \%$ (3143) of those aged 70 years or older were examined (Fig. 1).

Pelvic examinations per 1000 women ranged from 6.6 to 43.9 across hospital referral regions (Fig. 2). Fee-forservice gynecologists performed two thirds $(29,324)$ of pelvic examinations with the mean age of women examined being 1.1 years higher than at fixed salary gynecologists (47.8 vs. 46.7 years). Colposcopy was used in $1.6 \%$ (249) and ultrasound in $74.5 \%(11,810)$ of appointments at fixed salary gynecologists, while fee-for-service gynecologists used colposcopy in $49.2 \%(14,427)$ and ultrasound in $96.2 \%(28,216)$ of appointments (Fig. 3). Differences in use of colposcopy $(p<.001)$ and ultrasound $(p<.001)$ between provider types were statistical significant.

In addition $87.3 \%(29,324)$ of appointments in private practice had a procedural code for "complete examination performed by a specialist."

Additional analysis showed that there were 2013 appointments within publicly funded specialized health care for cervical screening appointments annually. Cervical screening constituted $4.3 \%$ of the combined number of appointments for cervical screening and routine pelvic examinations. The use of ultrasound was equivalent in appointments for cervical screening and routine pelvic examinations (91.3 vs. 88.6\%). Both fixed salary and fee-forservice gynecologists used colposcopy more frequently in appointments for cervical screening compared to routine pelvic examinations. Fixed salary gynecologists used colposcopy in 9.8\% (13) of cervical screening appointments (routine pelvic examination: 1.2\%). The corresponding number fee-for-service gynecologists was 69.8\% (1310) (routine pelvic examination: 49.2\%). Fee-for-service gynecologists performed 93.3\% (1877) of cervical screening examinations. Out of these $87.4 \%$ (1641) had a reimbursement code for "complete examination performed by a specialist." Adding cervical screening appointments to the analysis of regional variation caused minor sequence replacements for three regions while the national extent of variation did not change (Additional file 1).

In 16.5\% (7472) of appointments one or more secondary diagnoses were registered. During the 3 year period there were 856 different secondary diagnoses from almost all 


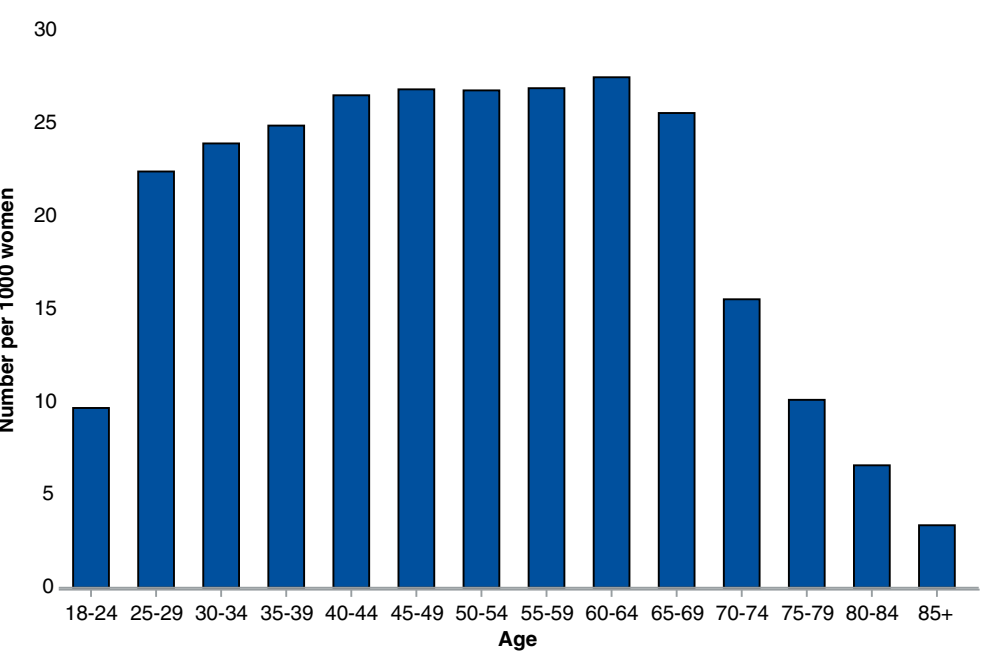

Fig. 1 Number per 1000 women receiving routine pelvic examinations by age groups. Annual mean for the years 2014-16

chapters in ICD-10. The variation in use of colposcopy and ultrasound between appointments with and without secondary diagnoses was minimal compared to the differences between fixed salary and fee-for-service gynecologists (Table 2).

Excluding appointments with secondary diagnoses in the analysis of regional variation caused minimal sequence replacements of five regions (Additional file 2).

\section{Discussion}

\section{Principal findings}

Routine pelvic examinations are widespread in Norway. Annually, 22.2 per 1000 adult women received a pelvic examination that is recommended against. The variation across hospital referral regions was extensive and ranged from 6.6 to 43.9 per 1000 women. Gynecologists with fixed salaries performed colposcopy in $1.6 \%$ and ultrasound in $74.5 \%$ of appointments, while fee-for-service gynecologists performed colposcopy in $49.2 \%$ and ultrasound in $96.2 \%$ of appointments. Fee-for-service payments for gynecologists seem to drive the utilization of colposcopy and ultrasound in routine pelvic examinations.

\section{Interpretation}

This is the first study to document the widespread use of unwarranted routine pelvic examinations in Norway. The great majority of examinations were performed on women aged 25-69 years. The Norwegian Cervical

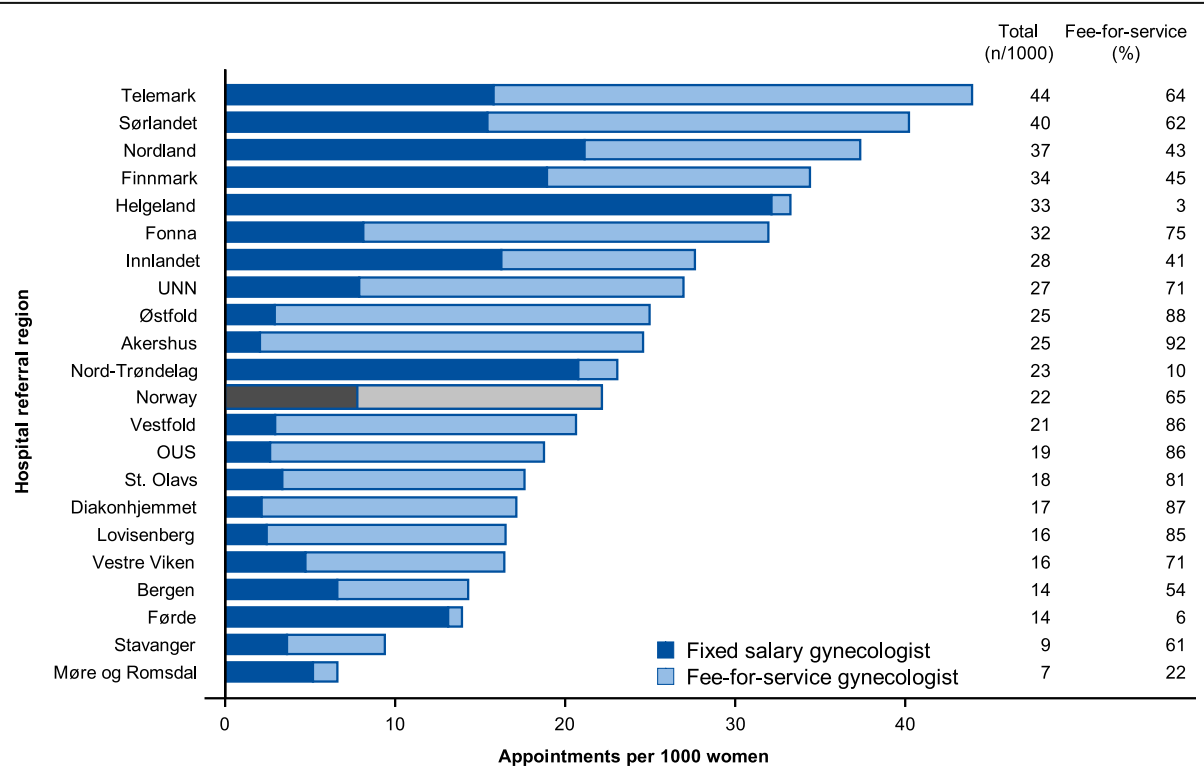

Fig. 2 Age-standardized number of appointments for routine pelvic examination per 1000 women by hospital referral region and type of provider 


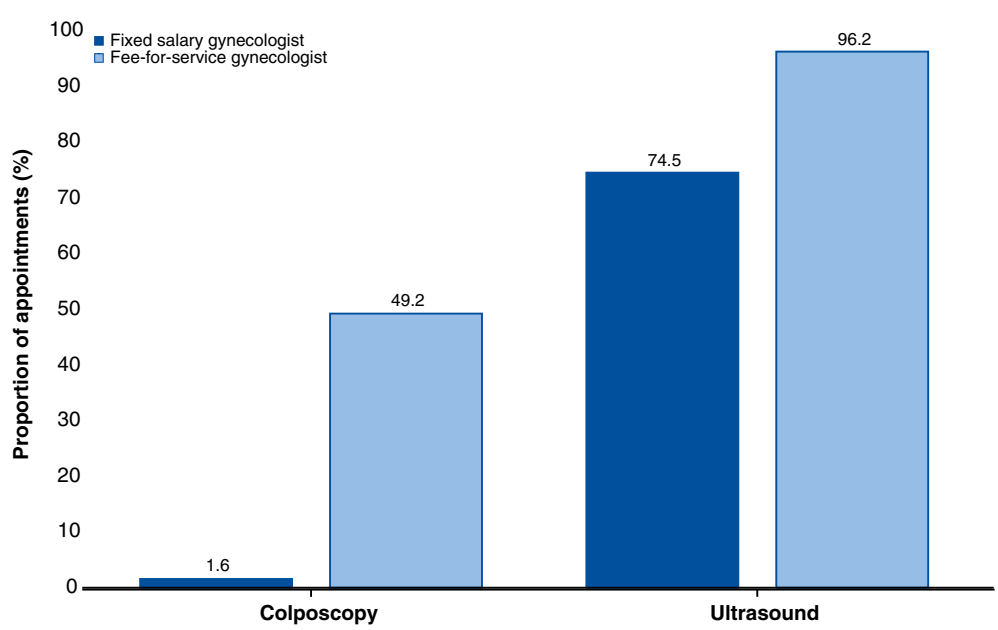

Fig. 3 Proportion (\%) of appointments with colposcopy and ultrasound in routine pelvic examinations by comparison of fixed salary and fee-for-service gynecologists

Cancer Screening Programme recommends and reminds all women between the age of 25 and 69 years to have a cytology test done every 3 years [19]. The correlation between cervix screening age and the age distribution in this study indicates that a large proportion of women with a routine pelvic examination may have had the extended examination as part of cervix screening. The number of appointments for each woman was 1.14 during the 3 years study period, which further strengthens this interpretation.

The real extent of routine pelvic examination in specialized health care seems to be higher than our study reveals, as the content of health care delivered in cervical screening appointments is equivalent to what is demonstrated in routine pelvic examinations. Pelvic examination, pelvic ultrasound and colposcopy are not indicated in asymptomatic women and are not part of The Norwegian Cervical Cancer Screening Programme, unless the result of the cytology test shows cause for concern [19]. There are separate ICD-10 codes for abnormal cervical cytological findings [15]. If women in our study actually were referred

Table 2 Colposcopy and ultrasound in routine pelvic examinations by comparison of payment model and whether or not the appointment had a registered secondary diagnosis. Annual mean for the years 2014-16

\begin{tabular}{llllll}
\hline & \multicolumn{2}{l}{ Fixed salary gynecologist } & & \multicolumn{2}{l}{$\begin{array}{l}\text { Fee-for-service } \\
\text { gynecologist }\end{array}$} \\
\cline { 2 - 3 } & \multicolumn{2}{l}{ Secondary diagnosis } & & Secondary diagnosis \\
\hline Outcomes & No & Yes & & No & Yes \\
& $(n=14,314)$ & $(n=1540)$ & & $(n=23,393)$ & $(n=5932)$ \\
Colposcopy, & $1.5 \%(220)$ & $1.8 \%(28)$ & & $47.3 \%$ & $56.8 \%$ \\
\% (n) & & & & $(11061)$ & $(3366)$ \\
Ultrasound, & $74.2 \%$ & $77.6 \%$ & & $95.7 \%$ & $98.4 \%$ \\
$\%(n)$ & $(10,616)$ & $(1195)$ & & $(22,381)$ & $(5835)$ \\
\hline
\end{tabular}

to specialized health care for routine testing within The Norwegian Cervical Cancer Screening Programme, our results demonstrate overuse of specialist health care services as cervical screening is supposed to be a primary care undertaking. This reflects a recently observed shift from primary to specialized health care for insertion of intrauterine contraception [20]. The finding of high numbers of colposcopy, ultrasound, and "complete examinations" in cervical screening appointments adds to this overuse. Based on our findings, we argue that primary care physicians should perform cervix screening.

Concomitant cervix screening cannot explain the extensive regional variation observed. Neither can differences in morbidity across the regions, as the women examined were by definition healthy. Geographical variation is shown to be associated with supply sensitive care [21]. The extent of variation in the present study points to examinations that are dependent on local health care practice and supply.

While the American College of Physicians, the Canadian Task Force on Preventive Health Care and the American Academy of Family Physicians strongly recommend against routine pelvic screening examinations, the debate is not settled. The US Preventive Services Task Force Recommendation Statement concludes "that the current evidence is insufficient to assess the balance of benefits and harms of performing screening pelvic examinations" [22]. The American Congress of Obstetricians and Gynecologists reaffirmed in 2016 their Committee Opinion which purpose is "to explain the need for annual assessments" albeit "at this time, this recommendation is based on expert opinion" [23].

The academic ambiguity concerning routine pelvic examinations might be reflected in our findings of extensive regional variation. As all the appointments required 
a referral, the regional variation might be explained by regional differences in referral pattern. However our study cannot answer if the observed variation is due to regional differences in: supply (i.e. the number of gynecologists to refer to); professional belief in and tradition for routine examinations; or the proportion of examinations performed by primary care physicians and gynecologists, respectively.

Either way, there is no pelvic screening program in Norway. Both the extensive regional variation and the extent of routine pelvic examinations per se are unwarranted in regard to the Norwegian Patients' Rights Act [14] and in regard to the Norwegian Medical Associations concerns on opportunistic screening [24].

Health expenditures are increasing worldwide and account for more than $12 \%$ of gross domestic product in OECD countries [25]. Apart from Luxembourg, no country spends more on publicly financed health care per capita than Norway [26]. It is recognized that fee-for-service reimbursement is the most important driver of high medical expenditures in the United States [27]. Fee-for-service in primary care has been reported to be associated with more visits, diagnostic tests and referrals compared to salary payment, though evidence is limited [28]. Ransom et al. have demonstrated that elective gynecological procedures are performed more frequently under fee-for-service than capitation payment [29]. The present study supports these findings as fee-for-service gynecologists used colposcopy and ultrasound 31.2 and 1.3 times more often than gynecologists with fixed salaries, respectively. Fee-forservice gynecologists have an economic incentive to extend the examination not only through the tariff for colposcopy and ultrasound, but also through reimbursement for "complete examination." This code was used in 87.3\% of fee-for service appointments.

Theoretically, patient preferences might explain some of the differences between provider types and also the regional differences. However there is no evidence that patient preferences have much impact on regional variation [30]. It is highly unlikely that healthy women referred to fixed salary physicians opt out colposcopy while the majority of women examined by fee-forservice gynecologists actively want this procedure. Moreover colposcopy and ultrasound are advised against in the screening setting, and should not be an offer within publicly funded healthcare regardless of preferences. Our results strongly imply that fee-for-service payments for gynecologists skyrocket the use of colposcopy and drive the use of "complete examinations" and ultrasound in pelvic examinations of asymptomatic women.

Recalibrating fee-for-service payments is recommended as one measure to constrain unsustainable health care expenditures [27]. Based on our findings, we argue that reimbursements for routine pelvic examinations including complete examination, colposcopy and ultrasound in women not registered with any symptom, complain or diagnosis should be discontinued. If gynecologists perform cytology screening in healthy women, any extra reimbursement should be removed.

\section{Generalizability}

To our knowledge, no other studies have quantified the national extent of routine pelvic examinations within publicly funded specialized health care. In Norway there has never been a national guideline recommending pelvic examination in asymptomatic women, nor a screening program for ovarian cancer. "Well-woman visits" [23] are not advocated by any Norwegian health authorities and the majority of women are unfamiliar with the practice. It is reasonable to believe that Norway scores relatively low on the number of routine pelvic examinations compared to countries with traditions and recommendation for annual assessments, and countries with a higher degree of fee-for-service-reimbursements for gynecologists.

This study only quantifies the use of pelvic examinations within publicly funded specialized health care. Private gynecologists with public funding constitute $43.5 \%$ of all private gynecologists in Norway [31]. The remainders are privately paid. The number of routine pelvic examinations paid out-of-pocket is unknown, as is the number performed by primary physicians. There is no reason to believe that privately paid gynecologists perform routine pelvic examinations any less than publicly funded gynecologists. On the contrary, privately paid gynecologists commonly advertise for routine pelvic examinations, hence, we believe that our study substantially underestimates the total amount of unwarranted pelvic examinations in Norway.

\section{Strengths and limitations}

The major strength of the study is the inclusion of all Norwegian adult women and that the studied codes give the basis for actual reimbursements paid to hospitals and fee-for-service gynecologists. Registration and reporting of appointments is compulsory and economically important for both hospitals and fee-for-service gynecologists. Correct reporting is focused on and stressed in both settings.

There are several limitations inherent in the methodology of register studies. Code practice may vary across regions. Underreporting of secondary diagnosis is expected [32]. Fee-for-service gynecologists get reimbursement according to the procedures they perform, while fixed salary gynecologists neither get compensated personally nor get more reimbursements to the hospital by performing colposcopy or ultrasound in routine pelvic examinations. Hence, it is possible that fee-for-service gynecologists are more thorough in their reporting, and that the actual use 
of colposcopy and ultrasound especially in hospitals is underreported. Still, it is highly unlikely that this can explain the huge differences observed.

\section{Conclusions}

Annually, 22.2 per 1000 adult women in Norway received a publicly funded pelvic examination that is recommended against. The variation across regions was extensive. Our results strongly indicate that fee-for-service payments for gynecologists skyrocket the use of colposcopy and increase the use of ultrasound in routine pelvic examinations. We argue that the reimbursement for these examinations should be discontinued, not only as a measure to constrain the unsustainable growth in health care expenditures, but also for the wellbeing of healthy women.

\section{Additional files}

Additional file 1: Age-standardized number of appointments for routine pelvic examination and cervical screening per 1000 women by hospital referral region and type of provider. (PDF $146 \mathrm{~kb}$ )

Additional file 2: Age-standardized number of appointments for routine pelvic examination per 1000 women by hospital referral region and type of provider. Appointments with secondary diagnoses are excluded. (PDF $146 \mathrm{~kb}$ )

\section{Abbreviations}

ICD-10: The International Classification of Diseases version 10; NCMP: The Norwegian Classification of Medical Procedures; NCRP: The Norwegian Classification of Radiological Procedures; NCSP: The NOMESCO Classification of Surgical Procedures; NPR: The Norwegian Patient Registry

\section{Acknowledgements}

Not applicable

\section{Funding}

The publication charges for this article have been funded by a grant from the publication fund of UiT The Arctic University of Norway. The publication fund had no influence in the design of the study, the collection, analysis, or interpretation of data or in writing the manuscript.

\section{Availability of data and materials}

The data that support the findings of this study are available from The Norwegian Patient Registry and Statistics Norway, but restrictions apply to the availability of these data, which were used under license for the current study, and so are not publicly available. Data are however available from the authors upon reasonable request and with permission of The Norwegian Patient Registry.

\section{Authors' contributions}

IMR conceptualized the study. LL undertook data extraction. IMR and LL undertook data analysis. AR, OHF, LL and IN made substantial contributions to design, data selection, methods, statistical analyses, and interpretation of findings. IMR drafted the manuscript. All authors critically revised the paper for important intellectual content and approved the final manuscript.

\section{Ethics approval and consent to participate}

The Norwegian Data Inspectorate licensed the data registry at Centre for Clinical Documentation and Evaluation (ref. 15/00271-2/CGN and 16/002892/CGN). Further ethical approval was not required according to Norwegian law $[33,34]$. Data from the Norwegian Patient Registry has been used in this publication. The interpretation and reporting of these data are the sole responsibility of the authors, and no endorsement by the Norwegian Patient Registry is intended nor should be inferred.
Consent for publication

Not applicable

Competing interests

The authors declare that they have no competing interests.

\section{Publisher's Note}

Springer Nature remains neutral with regard to jurisdictional claims in published maps and institutional affiliations.

\section{Author details}

'Department of Clinical Medicine, UiT The Arctic University of Norway, Tromsø, Norway. ${ }^{2}$ Centre for Clinical Documentation and Evaluation, Northern Norway Regional Health Authority, Tromsø, Norway. ${ }^{3}$ Department of Obstetrics and Gynaecology, University Hospital of North Norway, Tromsø, Norway. ${ }^{4}$ Department of Community Medicine, UiT The Arctic University of Norway, Tromsø, Norway. ${ }^{5}$ Division of Surgery, Oncology and Women's Health, University Hospital of North Norway, Tromsø, Norway.

Received: 15 September 2017 Accepted: 13 November 2017 Published online: 21 November 2017

\section{References}

1. Qaseem A, Humphrey LL, Harris R, Starkey M, Denberg TD. Clinical guidelines Committee of the American College of physicians. Screening pelvic examination in adult women: a clinical practice guideline from the American College of Physicians. Ann Intern Med. 2014;161(1):67-72.

2. Tonelli M, Connor Gorber S, Moore A, Thombs BD. Canadian task force on preventive health care. Recommendations on routine screening pelvic examination: Canadian task force on preventive health care adoption of the American College of Physicians guideline. Can Fam Physician. 2016;62(3):211-4.

3. The American Academy of Family Physicians. Clinical Practice Guideline: Screening Pelvic Examination in Adult Women. 2014. http://www.aafp.org/ patient-care/clinical-recommendations/all/screeningpelvicexam.html. Accessed 7 Nov 2017.

4. Cantor SB, Cardenas-Turanzas M, Cox DD, Atkinson EN, Nogueras-Gonzalez GM, Beck JR, et al. Accuracy of colposcopy in the diagnostic setting compared with the screening setting. Obstet Gynecol 2008;111(1):7-14.

5. American College of Obstetricians and Gynecologists. Ten Things Physicians and Patients Should Question. 2016. http://www. choosingwisely.org/societies/american-college-of-obstetricians-andgynecologists/. Accessed 7 Nov 2017.

6. Moyer VA. U. S. preventive services task force. Screening for ovarian cancer: U.S. preventive services task force reaffirmation recommendation statement. Ann Intern Med. 2012:157(12):900-4.

7. American Academy of Family Physicians. Clinical Preventive Service Recommendation - Ovarian cancer. 2012. http://www.aafp.org/patient-care/ clinical-recommendations/all/ovarian-cancer.html. Accessed 7 Nov 2017.

8. Buys SS, Partridge E, Black A, Johnson CC, Lamerato L, Isaacs C, et al. Effect of screening on ovarian cancer mortality: the prostate, lung, colorectal and ovarian (PLCO) cancer screening randomized controlled trial. JAMA. 2011; 305(22):2295-303

9. Jacobs IJ, Menon U, Ryan A, Gentry-Maharaj A, Burnell M, Kalsi JK, et al. Ovarian cancer screening and mortality in the UK collaborative trial of ovarian cancer screening (UKCTOCS): a randomised controlled trial. Lancet. 387(10022):945-56.

10. Society of Gynecologic Oncology. Don't screen low risk women with CA125 or ultrasound for ovarian cancer. 2013. http://www.choosingwisely.org/ clinician-lists/society-gynecologic-oncology-ovarian-cancer-screening-orultrasound-low-risk-women-ca-125/. Accessed 7 Nov 2017.

11. Benedet JL, Bertrand MA, Matisic JM, Garner D. Costs of colposcopy services and their impact on the incidence and mortality rate of cervical cancer in Canada. J Low Genit Tract Dis. 2005:9(3):160-6.

12. American Institute of Ultrasound in Medicine, American College of Radiology, American College of Obstetricians and Gynecologists, Society for Pediatric Radiology, Society of Radiologists in Ultrasound. AlUM practice guideline for the performance of ultrasound of the female pelvis. J Ultrasound Med. 2014;33(6):1122-30. 
13. Stewart FH, Harper CC, Ellertson CE, Grimes DA, Sawaya GF, Trussell J. Clinical breast and pelvic examination requirements for hormonal contraception: current practice vs evidence. JAMA. 2001;285(17):2232-9.

14. The Patients' Rights Act. 1999. https://lovdata.no/dokument/NL/lov/1999-0702-63 Accessed 7 Nov 2017.

15. The Norwegian Directorate of eHealth/World Health Organization. ICD-10: Den internasjonale statistiske klassifikasjonen av sykdommer og beslektede helseproblemer. https://ehelse.no/standarder-kodeverk-og-referansekatalog/ helsefaglige-kodeverk/kodeverket-icd-10-og-icd-11. Accessed 7 Nov 2017.

16. The Norwegian Directorate of eHealth. Prosedyrekodeverkene (Kodeverk for medisinske, kirurgiske og radiologiske prosedyrer, NCMP, NCSP og NCRP). https://ehelse.no/standarder-kodeverk-og-referansekatalog/helsefagligekodeverk/prosedyrekodeverkene-kodeverk-for-medisinske-kirurgiske-ogradiologiske-prosedyrer-ncmp-ncsp-og-ncrp. Accessed 7 Nov 2017.

17. The Norwegian Medical Association. Normaltariff for avtalespesialister 20152016. 2015. http://normaltariffen.legeforeningen.no/pdf/Normaltariff_2015. pdf. Accessed 7 Nov 2017.

18. SAS Institute Inc. SAS Enterprise Guide 7.1. http://www.sas.com/en_uS/ software/enterprise-guide.html. Accessed 7 Nov 2017.

19. The Cancer Registry of Norway. The Norwegian Cervical Cancer Screening Programme (NCCSP). https://www.kreftregisteret.no/en/screening/CervicalCancer-Screening-Programme/. Accessed 7 Nov 2017.

20. Pahle AS, Sorli D, Kristiansen IS, Deraas TS, Halvorsen PA. Practice variation in surgical procedures and IUD-insertions among general practitioners in Norway - a longitudinal study. BMC Fam Pract. 2017;18(1):7.

21. Wennberg JE. Tracking medicine: a Researcher's quest to understand health care. Oxford: Oxford University Press; 2010

22. Bibbins-Domingo K, Grossman DC, Curry SJ, Barry MJ, Davidson KW, Doubeni CA, et al. Screening for Gynecologic conditions with pelvic examination: US preventive services task force recommendation statement. JAMA. 2017;317(9):947-53.

23. The American College of Obstetricians and Gynecologists. COMMITTEE OPINION - Well-woman visit. 2012. https://www.acog.org/Resources-AndPublications/Committee-Opinions/Committee-on-Gynecologic-Practice/WellWoman-Visit. Accessed 7 Nov 2017.

24. The Norwegian Medical Association. FOR MYE, FOR LITE ELLER AKKURAT PASSE? Om variasjon, over- og underforbruk i helsetjenesten. 2016. https:// legeforeningen.no/PageFiles/14533/For\%20mye for\%20lite\%20eller\%20akkurat\%20passe.pdf. Accessed 7 Nov 2017.

25. The World Bank. Health expenditure, total (\% of GDP). http://data. worldbank.org/indicator/SH.XPD.TOTL.ZS?locations=OE. Accessed 7 Nov 2017.

26. OECD. OECD health expenditure database. http://stats.oecd.org/Index. aspx?DataSetCode=SHA. Accessed 7 Nov 2017.

27. Schroeder SA, Frist W. National Commission on physician payment R. Phasing out fee-for-service payment. N Engl J Med. 2013;368(21):2029-32.

28. Gosden T, Forland F, Kristiansen IS, Sutton M, Leese B, Giuffrida A, et al. Capitation, salary, fee-for-service and mixed systems of payment: effects on the behaviour of primary care physicians. Cochrane Database Syst Rev. 2000:3:CD002215.

29. Ransom SB, McNeeley SG, Kruger ML, Doot G, Cotton DB. The effect of capitated and fee-for-service remuneration on physician decision making in gynecology. Obstet Gynecol. 1996;87(5 Pt 1):707-10.

30. Baker LC, Bundorf MK, Kessler DP. Patients' preferences explain a small but significant share of regional variation in medicare spending. Health Aff (Millwood). 2014;33(6):957-63.

31. legelisten.no. https://www.legelisten.no/gynekologer?service_type=pub. Accessed 7 Nov 2017.

32. Hagen TP, Iversen T, Moger TA. Risk adjustment in measurements of predicted mortality after myocardial infarction. Tidsskr Nor Laegeforen. 2016:136(5):423-7.

33. Regulations on the collection and processing of health data in the Norwegian Patient Registry. 2007. https://lovdata.no/dokument/SF/forskrift/ 2007-12-07-1389. Accessed 7 Nov 2017.

34. Act of 18 May 2001 No. 24 on Personal Health Data Filing Systems and the Processing of Personal Health Data (Personal Health Data Filing System Act). 2001. https://www.regjeringen.no/no/tema/helse-og-omsorg/folkehelse/Actof-18-May-2001-No-24-on-Personal-Health-Data-Filing-Systems-and-theProcessing-of-Personal-Health-Data-Personal-Health-Data-Filing-System-Act-/ id224129/. Accessed 7 Nov 2017.

\section{Submit your next manuscript to BioMed Central and we will help you at every step:}

- We accept pre-submission inquiries

- Our selector tool helps you to find the most relevant journal

- We provide round the clock customer support

- Convenient online submission

- Thorough peer review

- Inclusion in PubMed and all major indexing services

- Maximum visibility for your research

Submit your manuscript at www.biomedcentral.com/submit
Biomed Central 